\title{
A CONSTRUÇÃO METODOLÓGICA DO CAMPO: ETNOGRAFIA, CRIATIVIDADE E SENSIBILIDADE NA INVESTIGAÇÃO
}

\author{
Bernadete Maria Dalmolin* \\ Stella Maris Brum Lopes** \\ Maria da Penha Costa Vasconcellos ${ }^{\star \star *}$
}

\author{
As vezes nossas posturas profissionais nos \\ "impedem de analisar as narrativas mais abrangentes \\ do imperialismo e de partilhar a responsabilidade coletiva \\ de entender os múltiplos espaços \\ que nos mapeiam tática e estrategicamente..." \\ (McLaren, 2000, p. 115)
}

\begin{abstract}
RESUMO: Este artigo apresenta reflexões sobre o processo metodológico de duas pesquisadoras na área da saúde pública que estão buscando na etnografia contribuições para seus estudos. Focaliza aspectos da etnografia nas sociedades contemporâneas e a partir das atividades de campo, apresenta a construção do pesquisador neste caminho de pesquisa, sinalizando algumas dificuldades que envolveram essa trajetória. Sugere, com isso, que a cooperação entre os diferentes saberes é altamente desejável, dada a complexidade dos fenômenos sociais de nosso tempo.
\end{abstract}

PALAVRAS-CHAVE: campo de pesquisa, etnografia, metodologia qualitativa.

* Enfermeira; Mestre em Saúde Pública e Doutoranda do Programa de Pós-Graduação em Saúde Pública da Universidade de São Paulo; Professora da Universidade de Passo Fundo/RS do Curso de Enfermagem; e Técnica Científica da Secretaria de Estado da Saúde do Rio Grande do Sul. e-mail: berna@upf.com.br

** Fonoaudióloga; Mestre em Saúde Pública e Doutoranda do Programa de Pós-Graduação em Saúde Pública da Universidade de São Paulo; Professora da Universidade do Vale do Itajaí do Curso de Fonoaudiologia. Rua Uruguai, 458, Centro - CEP 88302-202, Itajaí-SC. e-mail: stbrum@terra.com.br

*** Psicóloga, Professora e orientadora do Programa de Pós-Graduação em Saúde Pública da Faculdade de Saúde Pública da Universidade de São Paulo, Av. Dr. Arnaldo, 715. CEP 01246-904, São Paulo-SP e-mail: mpvascon@usp.br 


\section{INTRODUÇÃO}

O objetivo deste artigo é discutir a importância da etnografia como recurso metodológico em pesquisas na área da saúde. Esta proposta surgiu da percepção sobre a carência de literatura referente à aplicação deste referencial, especialmente nas áreas de Fonoaudiologia e Enfermagem, nosso campo específico de atuação profissional.

Chama a atenção o fato de que, muitas vezes, as temáticas nestas áreas são tratadas a partir de vertentes teóricas que limitam a apreensão do sujeito da pesquisa em sua condição de "outro" (no sentido antropológico), restringindo, dessa forma, o desvendamento de aspectos, a nosso ver, relevantes sobre o pesquisado, como é o caso dos fenômenos sócioculturais, também constitutivos deste sujeito.

O que parece prevalecer na Enfermagem e na Fonoaudiologia é um olhar mensurador sobre as questões de saúde, com ênfase nos aspectos institucionais e instrumentais do seu fazer. As questões de cunho cultural têm passado a margem ou, se abordadas, emergem como fatores causais ou como impedimento ao sucesso das intervenções dos profissionais de saúde.

Esta situação não é exclusiva destas áreas. ADORNO e CASTRO (1994) chamam a atenção para o fato de que, na maioria das vezes, a aproximação com as abordagens qualitativas acabam se restringindo apenas à apropriação de técnicas. Estes autores consideram que a metodologia qualitativa, ao possibilitar um exercício reflexivo de apreensão da realidade, exige mais do que a incorporação pura e simples de técnicas. Como resultado do "enquadre" da realidade que manifesta a relação sujeito/objeto, a relação estabelecida nesta apreensão requer o desenvolvimento de uma outra sensibilidade, na qual o pesquisador precisa estar disponivel para rever conceitos e concepções, estabelecendo uma comunicação com a multiplicidade de perspectivas que cercam os membros desta relação.

Entre as metodologias qualitativas possiveis para esta comunicação, está a abordagem etnográfica que traz novas contribuições, ao privilegiar a compreensão dos padrões culturais, desnaturalizando assim, as construções sobre a saúde e a doença.

Como pesquisadoras em Saúde Pública, estamos nos dispondo a refletir sobre uma maneira de abordar as relaçōes sociais que envolvem nossos objetos de pesquisa: os transtornos mentais e a comunicação. 
Este artigo faz uma breve abordagem da etnografia no contexto contemporâneo e, num segundo momento, a partir das reflexões sobre as atividades de campo, apresenta a construção do pesquisador neste caminho de pesquisa. A base destas reflexões foi a releitura dos diários de campo, produzidos durante duas pesquisas realizadas por nós, sendo elas: Cultura, Linguagem e Fonoaudiologia: uma escuta do discurso familiar no contexto da saúde pública, realizada em Zimbros, município de Bombinhas/SC no ano de 2000 e O lugar dado ao sofrimento psíquico pelos moradores de uma comunidade urbana do município de Passo Fundo/RS, iniciada em 2001. Estes diários ${ }^{1}$ referem-se a nossa primeira experiência com este tipo de pesquisa, por este motivo nos possibilitaram captar as apreensões vividas no processo.

\section{SOMOS CAPTURADOS POR UMA METODOLOGIA}

A escolha de um caminho para as nossas investigações não ocorre aleatoriamente, mas depende do objeto de pesquisa, do enfoque ou de que lugar desejamos abordá-lo. Deixar-se envolver por esta perspectiva não é perder o rumo, mas abrir-se para novas possibilidades de conhecimento do objeto de pesquisa. Ao deixá-lo "falar" ele pode nos conduzir a procedimentos diversificados e mais abrangentes antes não pensados. É o que nos parece ocorrer com a abordagem etnográfica.

O chamado saber técnico, que temos construído enquanto enfermeira e fonoaudióloga sanitaristas, muitas vezes nos restringe o acesso e nos fecha a possibilidade de percebermos o pesquisado como o "outro", nas suas dimensões sociais e culturais. Por isso, a necessidade de desenvolver estudos fora das instituições que oferecem serviços de saúde.Trata-se de um exercício para sair do nosso circuito cotidiano que pode nos limitar e não nos permitir compreender melhor a trajetória do outro que vive/convive com experiências de saúde e doença.

Nesse sentido, a busca de ferramentas metodológicas na Antropologia nos aproxima da dinâmica do grupo social estudado, auxiliando na compreensão do sentido dessas experiências e das estratégias que lançam mão para enfrentar o cotidiano.

\footnotetext{
1 Os trechos dos diários de campo serão destacados no texto, sendo que os referentes a pesquisa Cultura, Linguagem e Fonoaudiologia: uma escuta do discurso familiar no contexto da Saúde Pública serão apresentados em itálico diferenciando-o dos trechos da pesquisa "O lugar dado ao sofrimento psíquico pelos moradores de uma comunidade urbana do município de Passo Fundo/RS.
} 
Seu local de moradia, sua história, suas redes sociais compõem o cenário do estudo, pois compreendermos que esse processo, que faz parte da vida das pessoas, repercute na sua condição de saúde/doença.

ADORNO E CASTRO (1994) salientam que este olhar para as condições de vida das pessoas nos leva a querer conhecer as condições e o modo como estas se articulam e criam possibilidades de saúde e doença. Este conhecer traduz-se em uma experiência intersubjetiva "que conduz à revisão do sentido dado às coisas, podendo corresponder à necessidade de se situar, de achar um espaço específico na multiplicidade de espaços presente na contemporaneidade fragmentada" (p.182).

Esta experiência nos leva a um re-direcionamento metodológico como o proposto por MAGNANI (2002). Ao submeter à dinâmica urbana contemporânea a um tipo especial de abordagem etnográfica que ele chama de olhar de perto e de dentro, diferente de um outro olhar caracterizado como sendo de longe e de fora, o autor assinala que este é um diferencial aos aspectos que, num primeiro momento nos reportam a homogeneização e ao isolamento da vida nesses contextos.

MAGNANI (2002) e ADORNO E CASTRO (1994) enfatizam a necessidade de aproximação com o método etnográfico, cuidando para não reduzi-lo ou confundi-lo a uma técnica. Afinal, o método vai possibilitar novas leituras sobre a realidade, revelando a lógica e os desdobramentos de fatos inicialmente percebidos como fragmentados e sem lógica.

Esse novo é possibilitado a partir do confronto entre pesquisador e pesquisados através da relação que se estabelece entre as partes envolvidas tornando-os interlocutores, sendo essa relação uma via de mão dupla. Uma relação em que "ambos são dotados dos mesmos processos cognitivos que Ihes permitem, numa instância mais profunda, uma comunhão para além das diferenças culturais" (MAGNANI, 2002, p. 17). Assim, essa experiência permite, diferente de outras pesquisas, a troca, o envolvimento e a transformação de ambos.

Nesta direção, GEERTZ ressalta a questão da etnografia enquanto uma experiência interpretativa na qual o pesquisador não irá perceber aquilo que seus informantes percebem, mas com que, ou por meio de que, ou através de que os outros percebem (1989, p. 89).

MALINOWSKI (1980, p.47) já destacava que esses aspectos não estão claros, explícitos ou escritos no bojo de uma sociedade. Toda essa estrutura, segundo o autor, 
"encontra-se incorporada no meio mais evasivo de todos os materiais: o ser humano". No entanto, nem para os nativos de uma dada comunidade esses aspectos são, na maioria das vezes, compreensíveis, pois são "um resultado automático da interação das forças mentais da tradição e das condições materiais do meio".

Originariamente desenvolvida no estudo de sociedades de pequena escala, a etnografia tem como fundamento o "contato, confronto, diálogo com o outro", atualmente ela enfrenta a questão de como desenvolver estudos em centros urbanos e em culturas globalizadas. Sobre o enfrentamento destas questões Magnani faz uma reflexão a respeito de que modo essa ciência pode lidar com a complexidade das cidades contemporâneas.

Retomando os trabalhos de outros teóricos da cidade, Magnani lembra que o processo de urbanização das grandes metrópoles pode ser explicado a partir de, pelo menos, duas perspectivas: a da cidade enquanto caos, provocado pelo crescimento desordenado sem o devido acompanhamento de estrutura básica - saneamento, transporte, saúde, educação etc - e, a da cidade marcada pela ruptura, "conseqüência de saltos tecnológicos", que vão tornando ultrapassadas as estruturas urbanas anteriores e as formas de comunicação e sociabilidade que correspondem a estas formas. Nos dois enfoques, a cultura urbana sofre os mesmos revezes que evidenciam, em última instância, desagregação das formas de vida social marcada por segregação e violência. Guardadas as semelhanças de um mundo globalizado, questionase, se "o exercício da cidadania, das práticas urbanas e dos rituais da vida pública" não teriam nesse contexto, outros cenários (MAGNANI, 2002, p. 15).

Para este mesmo autor, é possivel construir um olhar etnográfico sobre os centros urbanos já que

são múltiplos, variados e heterogêneos conjunto de atores sociais que neles vivem, sobrevivem, trabalham, circulam, usufruem equipamentos ou deles são excluídos. Tomando como ponto de partida a perspectiva de cada um desses grupos é que se pode aceder a padrões de significados que ordenam comportamentos (MAGNANI, 1999, p. 104-105).

SAHLINS (1997, p. 41), também defende um lugar para a antropologia na contemporaneidade, através do conceito da cultura. Ele afirma que a cultura como o principal objeto da antropologia, nomeia e distingue o fenômeno que é "a organização da experiência e da ação humana por meios simbólicos." Destaca que, diferentemente de argumentações de que a globalização e outras peripécias do capitalismo absorvem e homogeneízam as culturas locais, etnografias desvendam essa lógica, mostrando que, padrões inéditos de 
comportamentos também acontecem e que, ao invés homegeneizar, intensificam e valorizam a cultura local.

A complexidade dessa sociedade contemporânea requer, nos termos de ADORNO e CASTRO (1994), uma nova discussão metodológica para o campo da saúde pública que transcenda o nível das técnicas de pesquisa para se inserir ao método enquanto um exercício reflexivo de apreensão de uma determinada realidade. Este exercício requer o esforço do pesquisador no sentido de "aprender a lidar com o incerto, o descontínuo, o flexível, o plural, o escorregadio" (p. 181), ao mesmo tempo em que integra, de modo complementar, questões antagônicas. Os autores defendem que "...cabe agora propor novas direções que certamente passam pela construção de uma ética entendida não só como construção de princípios, mas como o exercício de uma sensibilidade que tem como referência a experiência de mundos opostos, numa perspectiva que atende a transposição dos mundos..." (p. 183) mostrando que são indissociáveis e indispensáveis para a apreensão dessa realidade.

Assim, os habitantes da cidade apresentam lógicas, constroem trajetos que não se restringem ao espaço físico, extrapolando a noção de espaço material. Essas questões se tornam relevantes nas pesquisas, possibilitando-nos compreender os possiveis arranjos que os sujeitos vão criando no convívio com diferentes situações de vida.

BRANDÃO (1995, p. 138-139) nos chama a atenção para o cuidado que devemos ter com trabalhos de cunho etnográfico, para não congelarmos a vida interpessoal na estrutura social, pois o que se perde é mais do que a experiência da vida cotidiana:

perde-se também a compreensão que as lógicas das estruturas das relações entre familiares, entre parentes (...), entre vizinhos, entre tipos de sujeitos produtivos e/ou proprietários, entre patrōes e empregados, entre homens e mulheres, entre nós e entre nós e os outros, existem não somente dentro e entre as tramas de teias de instituições sociais (...) através das quais se trabalha, possui, produz, gera filhos, herda, etc, mas igualmente através de outras teias que tecem as vidas e, dentro, fora, a margem ou contra as organizaçōes oficiais da sociedade, geram os sistemas de vida, os símbolos e os significados de outra face da própria vida social.

Diante do exposto, pode-se perceber que a etnografia nos permite compreender a dinâmica das relações sociais nas sociedades contemporâneas. Entrar nessa dinâmica é sujeitar-se a correr riscos e ter que construir novas ferramentas para a compreensão dos nossos objetos de pesquisa. 
Por isso, a "captura" a que nos referimos acima, dá-se no sentido de interpelação ao objeto de pesquisa e aos possíveis caminhos metodológicos que ele nos indica. Cabe salientar que esse apelo a outra disciplina no sentido de dar suporte aos nossos objetos é um trabalho melindroso, principalmente pelo risco de, ao adentrarmos em outra "seara", fazermos leituras parciais e reducionistas. Mesmo assim, vale a pena pois o que nos move é a busca dessa interface no sentido de irmos superando os limites disciplinares que nos inviabilizam, muitas vezes, de enriquecer nossas pesquisas e criar outros caminhos propiciados por essa imbricação.

\section{EXPERIÊNCIAS ETNOGRÁFICAS: DOIS ACASOS}

PEIRANO (1992) salienta que na Antropologia não é possível ensinar a fazer pesquisa de campo como se ensina em outras abordagens metodológicas, pois, o desenvolvimento da mesma está diretamente ligado a biografia do pesquisador, ao objeto de pesquisa, ao enfoque teórico ou de que lugar desejamos abordá-lo, do contexto histórico mais amplo, das relações que se estabelecem entre o pesquisador e o campo de pesquisa, além dos imprevistos que fazem parte do pesquisar.

O trabalho etnográfico apresenta algumas questões sobre a inserção do pesquisador no campo e a relação que se estabelece com esses sujeitos. São questões que colocam o pesquisador de forma diferente do que habitualmente nos situamos. É um pesquisador em relação e que privilegia também um processo reflexivo sobre as suas impressões.

Como estas foram questões relevantes em nosso percurso de pesquisa, exemplificaremos com alguns trechos de nossos diários de campo, nosso processo de aproximação. Os diários de campo, são registros sistemáticos das atividades em campo, nele são anotadas descrições, trechos de fala, impressões, sentimentos, este material é lido e relido durante o processo da pesquisa para que novas interpretações sejam feitas ou questões sejam aprofundadas. Através dos diários levantou-se além de dados pertinentes ao contexto da pesquisa e seus sujeitos, também o movimento das pesquisadoras, movimento este destacado no presente artigo. 


\section{CHEGAR AO CAMPO: ENTRE O FORMALISMO E A ENTREGA}

Apesar da literatura pontuar que o campo é mais que o espaço real, percebemos que, inicialmente, precisamos do concreto, da descrição, de estabelecer nossas referências:

Meu primeiro dia de trabalho de campo: andei só de carro, tentando delimitar o espaço geográfico do bairro, conhecer o nome das ruas e lançar um primeiro olhar sobre a dinâmica desse local. Era um domingo à tarde. Com um mapa conseguido na Prefeitura Municipal de Passo Fundo comecei a circular pelas ruas. Fiz várias paradas para obter informaçōes com as pessoas que estavam andando ou, em frente a suas casas. Eu estava procurando identificar as ruas no meu mapa.

Preferi organizar meu texto de forma bem descritiva com algumas observações, e no final fiz uma síntese do que me foi familiar e o que não esperava (...) No inicio de Zimbros, vê-se ruas não pavimentadas, casas não muito agrupadas, existe a escola do Estado que tem $1^{g}$ e $2^{9}$ graus e é bem grande, há um ginásio de esportes ao lado. Na mesma região há a associação dos pescadores, o posto de gasolina e a farmácia. Freqũentam a escola pessoas de todos os bairros. Havia placa com o horário de saida de todos os ônibus.

Por não sermos antropólogas, acabamos por nos "engessar", ora não ultrapassando a descrição linear, ora tentando exercitar sobre o que era estranho e familiar, conforme os relatos acima. Sabíamos que não podíamos correr o risco de "cair na mera descrição ou recolha de dados a serem posteriormente trabalhados" deveríamos "delimitar o cenário, identificando marcos, reconhecendo divisas e não apenas anotando equipamentos e estruturas físicas" (MAGNANI, 2000, p. 37).

A própria sistematicidade das caminhadas nos leva a reconhecer que o bairro só existe a partir do sentido que as pessoas Ihes dão. O cotidiano ganha força e, na medida em que se torna conhecido, cresce em nós, a questão da familiaridade e da estranheza.

Hoje me senti uma "estrangeira no pedaço". As pessoas me olhavam e eu não me sentia nada a vontade. A minha sensação de estranhamento me fazia pensar que a minha sorte era estar de carro. Fiquei preocupada com as dimensões e com a diversidade do bairro.

A fala estava evasiva demais, fiquei com a sensação que ela não queria me falar. Perguntou-me se eu era de Passo Fundo, após falar da minha cidade natal que é uma cidade conhecida e próxima de onde morava antes de migrar à Passo Fundo, senti que se soltou mais e me falou que 
se mudara de lá após a aposentadoria, pois seus filhos estavam todos ali. Tínhamos algo em comum!

Vemo-nos percebidas, reveladas no lugar do outro. Parece que existe uma rede que nos percebe sem palavras.

Depois fiz um "tour" por ZIMBROS, subi e desci os morros, tirei algumas fotos para fazer meus marcos de referência. Ao falar de um gato, saiu uma senhora de casa e foi falar comigo sendo bem direta: quem é você? que tá fazendo aqui? Conversamos um monte depois que lhe contei que não era dali. Ela respondeu logo vi, você não tem cara daqui.

Aos poucos o campo começa a tornar-se familiar e a sensação de estranhamento diminui, abrindo espaço para conhecer os "nativos" como sujeitos. De inicio, ficamos muito presas ao objetivo da pesquisa, considerando menos o fato de que o campo vai se revelando gradativamente, em tempo muitas vezes diferente do nosso, ou, de quando conseguimos nos desprender dos nossos (pré) conceitos em relação ao que nos é estranho:

Ao encontrar mães que eu já havia visto, me senti menos estranha ao lugar. Também de alguma forma elas me reconheceram, e acredito que aí está o ponto. Um profissional que chega em um lugar deve estar disponivel para ouvir, para que ai se crie um espaço de comunicação entre a população e ele.

Hoje não sei se pelas coisas que falaram no seminário ou pelas mães conhecidas, me senti menos diferente deles. Elas pararam de ser objetos diferentes a serem estudados. Ui que coisa feia! mas parece que de vez em quando vem forte a necessidade de ter um objeto de pesquisa bem delimitado e distante.

Estou um pouco preocupada com as minhas "buscas" no bairro. Acho que elas estão muito voltadas para um caminho mais conhecido (ex-pacientes,...). De qualquer forma, estou tentando tirar proveito de tudo isso. As aproximações estão me fazendo conhecer a realidade, seus itinerários, enfim, mediadores dos meus interesses. Se não for assim, como poderia ser?

\section{QUAL O MEU LUGAR NO CAMPO?}

Uma questão aparentemente banal mas que identificamos como recorrente em nossos diários é a da identificação. Pensamos até mesmo amparadas por leituras que, para podermos observar e entrar na dinâmica, seria interessante não revelarmos o objeto de nossa pesquisa. 
Mas tínhamos alguma "estrada" com o reconhecimento do nosso lugar profissional e nos deu muito trabalho sair deste trânsito. Esse processo gerava tensão na hora de nos apresentarmos, sentiamo-nos "pisando em ovos":

Novamente não perguntaram quem sou eu, acho que só eu que não descobri que elas já sabem quem sou. Fico pensando porque eu me fixo tanto nisso. Às vezes, acho que quero ser reconhecida pela minha diferença, será?? Aí vem de novo a contradição entre o discurso e 0 ato.

As pessoas foram receptivas e alguns me perguntaram: "quem a senhora está procurando?" Eu rapidamente explicava que eu era da UPF, estava querendo conhecer o bairro porque pretendia desenvolver um estudo no local.

Este movimento, por vezes, nos tornava surdas ao que as pessoas nos colocavam ou levava-nos a buscar espaços institucionais.

Ao chegar a Bombinhas vi o quanto precisava voltar a me referenciar. Então, novamente com a desculpa de começar a articular os grupos do R. retomei contato com a Secretaria de Educação e Saúde. Na Educação, encontrei a V. e A e fui cumprimentada por várias pessoas de lá. Destes encontros tirei meu pé, pois eles me deram um senso de pertencimento (é estranho ter a noção de pertencer como estrangeira, pois sei que meu acesso as coisas de lá é limitado). Voltei, então, a me sintonizar com Bombinhas.

$\mathrm{Na}$ relação que foi-se construindo, começamos também a identificar o local que eles nos dão. Sendo deslocadas daquele papel distante e alheio a comunidade:

nunca fui vista como a fonoaudióloga ou a professora da Universidade. Eu era chamada de "a moça do posto" pelos da rua e, "nêga", pelas pessoas com quem conversava.

Seu J. também me recebeu muito bem e após a minha apresentação me perguntou se eu trabalhava também em PF. Disse-Ihe que sim e onde. Ele logo me deu um lugar. A de alguém que fazia trabalho social. O padre já havia me chamado de voluntária e outras pessoas já haviam se referido a mim como alguém que quer ajudar os doentes...

Os sujeitos da pesquisa tornaram-se interlocutores. Começam a dar opiniões sobre o que teríamos que fazer ou não, arranjam formas de nos ajudar e também querem saber mais de nossas vidas: 
Você não quis casar? Não vai ter filhos? Como é a sua vida lá em Balneário, deve ser uma vida boa!

Ah Stella, nós olhamos ele ali na sala de espera, ficamos alegres. Pensamos: é o namorado dela. Achamos que não, pelo jeito deveria ser o seu professor, então te pedimos para nos ajudar. Acho que o seu professor ficou contente, não? Ele sabe que nós te aceitamos!

Dona J. me falou de varias pessoas "mentais", mas do A. sempre procurou falar pouco. Então também tem os reconhecidos, mas velados. O policial não temeu em me falar, mas os vizinhos preferem o silêncio. $O$ próprio J. e a dona $F$. que disseram conhecer todo o mundo ai nas redondezas, não mencionaram o nome dele que mora na rua paralela na mesma direção. Esquecimento? Lembrei que a dona F. me falou de um menino, já relatado, o J., mas me disse que ela falaria com a sua mãe, porque o pai do menino era bicheiro e tomava uns "fogo", então ela tinha que ver quando eu podia chegar lá.

Percebemos isto como marcas da nossa inclusão e não como empecilho ou viés na pesquisa. $E$, sutilmente, percebemos que eles também são incluídos, deixam de ser informantes e passamos a querer conhecê-los, criando-se o diálogo:

Ainda continuamos sem pediatra. Hoje não havia viva alma no posto, a não ser a l. (com a qual fiz uma besteira semana passada: ela, pela primeira vez, falou comigo. Como falou muito rápido, eu disse a ela que não tinha entendido, porque ela havia falado rápido. Ela disse que não falou rápido e se calou). Ai pensei: quem exclui quem? Pois sempre que chego no posto a F faz festa para mim, então é lógico que é bem mais fácil eu me aproximar dela do que da $I$. que só me olha de lado. Faz-me entrar numa reação típica minha, que é ignorar.

Para fechar o dia com "chave de ouro", a I falou um "monte" comigo. Primeiro em relação às comidas que ela faz, e a F comentava que 'pirão dágua em SP serve é para colar pipa'. Quando comentei que devia ter pernilongo pois eu estava coçando toda, aí elas começaram a comentar que já era horário da casa estar fechada e a l foi lá e fechou a porta. Depois me chamando pelo nome, perguntou se eu só ia ali e se voltaria hoje para Balneário, afinal já era noite.

O menino falou que a mãe dele queimou a chupeta no fogão na sua frente; a $F$ sugeriu que a mãe colocasse novalgina no bico que a criança logo largava, a mãe dizia que ele iria dar para o coelhinho e a 'moça do posto' falou: não adianta, criança só larga quando quer.

A opinião que me deixou mais confusa foi a da $F$, mas no final da manhã quando voltei para conversar com ela (que estava bordando), soube mais um pouco da sua vida. Ela disse que 
agora que estava voltando a fazer estas coisas e que isso era uma fuga. Quando os filhos cresceram ela decidiu correr atrás do tempo perdido, voltou a estudar, fez o curso de auxiliar e tentou vestibular para enfermagem duas vezes, na segunda estava para ser chamada, quando a prefeitura cortou as bolsas. Ela disse que achou que fosse enlouquecer já que estava bem deprimida, pois uma vez teve até de ir para uma clínica, então cultivando novamente este lado de casa leva a vida para não pensar no sonho que não conseguiu realizar. Disse que tem loucura para fazer medicina, acho que isso indica o por quê usar da medicina para 'tirar a chupeta'.

\section{DIÁRIOS: ENTRE RELATÓRIOS E REFLEXÕES}

Inicialmente os diários traziam só as nossas observações que primavam em ser o mais "neutras" possível, na esperança de traduzir, fielmente, o que víamos.

O bairro é imenso (em extensão territorial), moradias contrastantes, mas prevalecem casas "populares", construidas há mais tempo. Ao entrar nas partes mais distas do centro da cidade, pareceu-me que há mais identidade de bairro, ou seja, uma maior proximidade entre as pessoas. Vi pessoas reunidas nas áreas abertas das casas, pessoas caminhando pelas ruas, crianças brincando, pessoas jogando futebol [pelas camisetas, dois times] e várias pessoas assistindo, sentadas nas sombras ao lado do campo. Num outro espaço havia um bar, com várias pessoas conversando, ouvindo música e bebendo. Encontrei pessoas se deslocando para esse local. Pareceu-me que esses são alguns espaços de lazer que envolvem as pessoas do local num dia de domingo.

Só que, como que raptadas, aos poucos o que se estruturava como relatório começa a ter traços de diário. Nele expressamos os nossos sentimentos e reflexões sobre o campo.

Esse processo [de sucessivas idas ao centro comunitário] permite-me conhecer mais o cotidiano das pessoas do bairro, particularmente as que compartilham de um problema que é a hipertensão arterial, mas também me fez ver situaçōes de sofrimento, tanto por parte das pessoas que buscam atendimento e não encontram respostas, quanto por parte dos trabalhadores que não conseguem dar o melhor encaminhamento para as diferentes situaçōes que se apresentam. Estou me dando conta que o CC virou meu lugar de observação!!!

Comecei a andar pela rua que me é mais familiar. Passei na casa de Dona M., não encontrei ninguém. A casa estava com as janelas todas abertas, mas ninguém atendeu a porta. Sai e 
continuei a minha caminhada. O caminho estava tranqüilo como sempre. Poucas pessoas na rua e os que estão devem ser do local. Olham pra mim e parece que querem saber o que eu estou fazendo aqui. Continuo caminhando. Sinto-me uma "estranha no ninho". Já me senti assim outras vezes por aqui, particularmente quando as pessoas não me são familiares. É desagradável. Penso na importância de pertencer a um local e se sentir dele.

O meu percurso teve sentimentos muito diversos. Cedo quando passei em frente à casa de I. ela estava lá no mesmo lugar das outras vezes. Acenei-lhe e ela retribuiu e rapidamente entrou. Fiquei pensando na sua vida entre a sua casa e a rua, como seria? Quando parei na casa de M.E. me senti um tanto intrusa. Perguntei-me com que direito eu poderia chegar na sua casa, me apropriando de uma informação e questionar a sua vida pessoal.

No processo de construção fomos percebendo a importância de voltar e reler os diários. Esta segunda interpretação traz contribuições para a nossa percepção enquanto pesquisadora e do momento que vivemos na pesquisa.

Hoje sai muito incomodada de Bombinhas, meu trabalho me inquietava pois estava questionando muito o que eu queria saber. Num dos devaneios pensei em desistir, pois veio a idéia que eu não queria mais saber o que as mães pensavam do desenvolvimento da linguagem dos seus filhos e muito menos o que isso tinha de cultural. Estava intrigada em como as mulheres constroem este papel: ser mãe.

Agora no meio da noite, veio uma idéia que me parece muito lógica, meu trabalho tem a ver com um processo de subjetivação que a mulher faz ao construir este lugar de mãe. Então para descobrir a dimensão do cultural nas práticas das mães em relação a linguagem, tenho de ter uma ação que não as reduza a dimensão matema e sim que una esta dimensão à sua condição de mulher que vive em uma comunidade como a de Zimbros. Talvez isto sempre tenha estado no meu trabalho mas de forma subliminar. Agora ficou claro por um processo pessoal e uma experiência clínica

Troquei informações sobre o meu trabalho com uma pessoa da minha relação, contando-lhe o que estava encontrando. Falei-lhe um pouco do caso de $L$. e da interpretação que fazem do processo de adoecimento. Disse-lhe que nós tínhamos muito a aprender com essas pessoas, pois achava que eles lidavam com o sofrimento de uma maneira bem mais humana do que a nossa forma oficial de tratar. Estou pensando no paralelo que de certa forma a mãe de L. fez com o hospital psiquiátrico e o Centro de Umbanda, colocando num toda a negatividade e em outro toda a positividade. É claro que isso precisa de 
um filtro, de uma análise que não a do senso comum, mas ela trouxe elementos importantes, como o afeto pela filha, a participação da família, o não conformismo de ter uma filha louca dentro de casa.... Pareceme que nós profissionais não conseguimos chegar próximo do sofrimento das pessoas, particularmente de um sofrimento que mobiliza, as vezes uma comunidade inteira, digo melhor, as pessoas das proximidades, lideranças, etc.

\section{CONSIDERAÇÕES FINAIS}

Talvez BRANDÃO (2002) possa traduzir nossa síntese quando se refere ao momento de ouvir "[...] nos dias de hoje, quem fala de uma fila longe do palco poderia estar nele, falando de perto. E quem responde bem poderia estar lá, entre os outros e as outras, ouvindo em silêncio. Ouvindo e ... aprendendo."

Incorporar o campo como um espaço que não está dado, que vai tomando sentido, se singularizando a partir do mergulho, das possibilidades criadas pelo conjunto (pesquisador e pesquisados) no decorrer da pesquisa, é elemento central em pesquisas dessa natureza e um desafio para o pesquisador. Esse processo sinuoso e complicado é um exercício que requer tempo, sensibilidade e muita paciência, principalmente para suportar a ansiedade de quem aprendeu a negociar individualmente com o(s) seu(s) sujeito(s) de pesquisa.

Além do desenvolvimento do ouvir, todos os outros sentidos nos são requeridos para novas construções simbólicas, pois não é apenas observar ou agir, trata-se de estabelecer novas relações. E alguns autores como SILVA (2001), MCLAREN (2000), CALDEIRA (1988), além dos já citados, nos permitiram ver que este lugar do autor no trabalho etnográfico é uma discussão da área, e é uma construção do percurso.

No nosso caso, a presença desse "mosaico" que compõe as múltiplas facetas desse momento da observação representou e continua a representar um desafio para a reflexão a respeito "do dentro e do fora", quando esses espaços devem ser construídos de forma circular ou espiral.

O uso dessa abordagem tem nos ajudado a orientar esse primeiro olhar, permitindo algumas classificações e fazendo um movimento dialético entre pesquisador e pesquisados que, acreditamos, possibilita a criação de algo novo a ser construído na continuidade de nossas pesquisas. Esse processo nos coloca "[...] um elo a mais na cadeia de reciprocidades... que, através do ofício de ida-e-volta..., se unem e entrelaçam vidas e idéias ao redor da 
construção cotidiana daquilo que dá ... a nossa razão de ser e de trabalhar" (BRANDÃO, 2002).

Ao lançar um olhar de fora sobre o nosso processo de pesquisa, pode-se dizer que 0 que trouxemos para o debate e a reflexão, foi a idéia de que ir a outras searas, não é aplicar uma técnica diferente de pesquisa, mas é implicar-se no processo de construção da pesquisa. E este processo vai fazendo parte da construção de nossa identidade de pesquisador, e no nosso caso pesquisadoras que sabem que não são antropólogas mas que ao serem tocadas pelo olhar antropológico questionam certas crenças da sua prática.

\section{REFERÊNCIAS BIBLIOGRÁFICAS}

ADORNO, R.C.F.; CASTRO, A.L de. O exercício da sensibilidade: pesquisa qualitativa e a saúde como qualidade. Saúde e Sociedade. São Paulo. v. 3, n. 2, p. 172-85,1994.

BRANDÃO, C.R. Lições do Sul: a educação popular na escola cidadã, 2002.

BRANDÃO, C.R. Partilha da vida. São Paulo: Cabral, 1995.

CALDEIRA, T.P. A pós-modernidade na antropologia. Novos estudos CEBRAP, São Paulo, n. 21, p.133-57, 1998.

GEERTZ,C. A interpretação das culturas. Rio de Janeiro: Guanabara Koogan, 1989.

MAGNANI, J.G.C. As cidades de "tristes trópicos". Revista de Antropologia, São Paulo, v. 42, n. 1 e 2, p. 98-111, 1999.

MAGNANI, J.G.C. De perto e de dentro: nota para uma etnografia urbana. Revista Brasileira de Ciências Sociais, v. 17, n. 49, p. 11-29, 2002.

MAGNANI, J.G.C. Quando o campo é a cidade: fazendo antropologia na metrópole. In: MAGNANI, J. G.; TORRES L. de L. (org.) Na metrópole: textos de antropologia urbana. 2 ed. São Paulo: Edusp/Fapesp, 2000: p. 12-53.

MALINOWSKI, B. Objetivo, método e alcance da pesquisa. In: GUIMARÃES, A.Z. Desvendando mascaras sociais. Rio de Janeiro: Francisco Alves, 1980. p.

MCLAREN, P. O etnógrafo como um 'flâneur' pós-moderno: reflexividade crítica e pós hibridismo como engajamento narrativo. In: MCLAREN, P. Multiculturalismo revolucionário. Porto Alegre: Artes Médicas Sul, 2000, p. 82-116. 
PEIRANO, M. A favor da etnografia. Rio de Janeiro: Relume-Dumará, 1992.

SAHLINS, M. O 'pessimismo sentimental' e a experiência etnográfica: porque a cultura não é um 'objeto' em extinção. Mana, Rio de Janeiro, v.3, n. 1, p. 41-73, 1997.

SILVA, A. Imaginários urbanos. São Paulo: Perspectiva; Bogotá, Convênio Andres Bello, 2001.

THE METHODOLOGICAL CONSTRUCTION OF THE FIELD: ETHNOGRAPHY, CREATIVITY AND SENSITIVITY IN THE INVESTIGATION

SUMMARY: This article presents reflections about the methodological process carried out by two researchers in the area of public health in search for contributions for their studies within ethnography. It also focuses on aspects of the ethnography in contemporary societies. From the field activities it depicts the construction of the researcher on the path of research, signaling some difficulties involved in trajectory. Thus this work suggests that the cooperation of the diverse kinds of knowledge is highly desirable given the complexity of the social phenomena of our time.

KEY WORDS: field of research, ethnography, qualitative methodology. 